\title{
The Extended Enterprise - Manufacturing and The Value Chain
}

\author{
Professor J. Browne, \\ CIMRU, \\ University College Galway, \\ Galway, \\ Ireland. \\ Tel : +353.91 .750414$ \\ Fax: +353.91 .562894 . \\ E Mail : Jimmie.Browne@ucg.ie
}

\begin{abstract}
The Extended Enterprise where core product functionalities are provided separately by different companies who come together to provide a customer defined product is made possible by the emerging integration of computing and telecommunications technologies. These technologies facilitate the development of competitive advantage by exploiting linkages in the value chain. If the challenge of CIM (Computer Integrated Manufacturing) was to realize integration within the four walls of the plants, the challenge to manufacturing systems analysts and researchers today is to support inter-enterprise networking across the value chain. Changes in product and process technologies and the emerging pressure for environmentally benign production systems and products further enhance this challenge.
\end{abstract}

Extended Enterprise, Value Chain.

Keywords

\section{LINKAGES IN THE VALUE CHAIN}

Writing in 1985 Porter introduced the concept of the Value Chain. In Porters' words 'value chain analysis helps the manager to separate the underlying activities a firm performs in 
designing, producing, marketing and distributing it's products or services". Value adding activities are the building blocks of competitive advantage and the value chain is a set of interdependent activities. Linkages in the value chain define the relationship between the way individual value adding activities are performed. Competitive advantage is also achieved by exploiting linkages, which usually imply efficient information flow and which facilitates the coordination of various value adding activities. For example manufacturing management has long recognised the value of efficient data flow between CAD and CAM systems and technical solutions have been proposed to exploit this linkage.

But of course linkages exist not only within the individual firm's internal value chain but also between an individual firm's value chain and that of it's suppliers and distribution channels. Again manufacturing companies have long recognised this and the Kanban ordering and delivery system seeks to exploit the linkage between final assemblers and their components supply chain, to achieve Just In Time delivery.

\section{INFORMATION TECHNOLOGY AND THE VALUE CHAIN.}

In more recent years the attraction of EDI (Electronic Data Interchange) technology is that it exploits the linkage between the value adding activities of individual firms in the value chain. For example, the ability to electronically share CAD data between specialist suppliers and their customers (the final assemblers of automobiles) in the automotive sector facilitates codesign, and reduces the time to market for new components and ultimately new cars.

Indeed recent developments in information technology and telecommunications are creating new linkages and increasing our ability to exploit old linkages. Keen (1991) used the terms 'Reach" and "Range" to articulate the impact of the new computing and telecommunications technologies on businesses. See Figure 1 below (taken from Browne, Sackett \& Wortmann

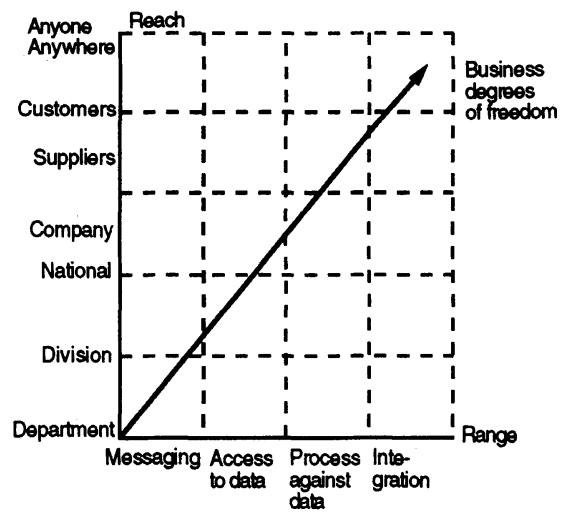

Figure 1 Business and Technology Integration. 
1994a). "Reach" refers to the extent that one can interact with other communications nodes in the ultimate it becomes anyone, anywhere. The recent explosive growth of the INTERNET is testimony to extended reach. "Range" refers to the data and information types that can be supported, ranging from simple electronic messaging between identical computer platforms to complex geometric and product data between hetrogeneous CAD systems on multivendor hardware and software platforms. Clearly the gradual expansion of the reach and range of these technologies provides opportunities to exploit linkages between value adding activities within individual firms or enterprises and indeed between firms and enterprises. But of course the availability of new technology - in this case tele-computing technology - is not sufficient reason to use it. Unless this technology creates competitive advantage it will not find widespread application.

Recent trends towards "focused factories", "core competencies", and the "outsourcing" of non-critical (in a competitive or critical success factor sense) activities provide opportunities for the emerging tele-computing technologies. Furthermore the emerging societal pressure on manufacturers to produce environmentally benign products using environmentally benign processes requires manufacturing firms to look beyond the "four walls of the manufacturing plant". Manufacturing companies must put in place systems which not only manufacture, distribute and service products but also collect at end of life, disassemble, recover or recycle and ultimately safely dispose of products. [See Tipnis 1993]. In effect the responsibility of the manufacturer is extended beyond that of providing and servicing a finished product.

As pointed out by Browne, Sackett and Wortmann (1994b), in the recent past the emphasis was on Computer Integrated Manufacturing and integration within the "four walls of the manufacturing plant". Today the emphasis is changing to include the supply chain to the manufacturing plant, the distribution chain from the plant to the ultimate customers and increasingly the end of life disposal or recycling issue.

The extent to which this change in emphasis has taken place can be seen in the workprogramme for research and technology development in Information Technologies of the 4th Framework Programme of the European Union; the domain 'Integration in Manufacturing' has a subsection entitled 'Logistics in the Virtual Enterprise' whose goal is to achieve an 'information logistics' infrastructure providing the required data at every step of the business process, to underpin the logistics of the supply and the distribution of materials and components'. One of the tasks which has been identified against this objective aims to develop 'innovative IT-based tools to model the interaction between companies forming the extended or virtual enterprise based on a distributed concurrent engineering and co-design approach, and covering all aspects of the product life cycle'. [European Commission, 1994a].

Not surprisingly the 'Industrial and Materials Technologies' workprogramme of the 4th Framework Programme shares a similar perspective. In the introduction to subsection 1.5 entitled 'Human \& Organisational Factors in Production Systems', this thinking is clearly set out viz; "... Competitive advantage is increasingly derived from dependency and interdependency between suppliers, component manufacturers, product assembly, distribution, sales and customers. The aim is the integration of new human, business and organisational structures as a 
key component of the new form of manufacturing systems, involving close intra-enterprise and inter-enterprise networking to develop customised products in very short lead times, whilst fully utilising human skills" [My emphasis; European Commission 1994b].

\section{WHAT IS THE EXTENDED ENTERPRISE?}

The Extended Enterprise, as suggested above arises from the convergence of a number of ideas:

1. In many businesses it is no longer possible or indeed desirable to achieve world class capability in all the key functional areas within a single organisation.

2. Manufacturing businesses recognise the value of the "Focused Factory" and are beginning to outsource non core activities.

3. Given 1 and 2 , it is now possible to provide core product functions separately by individual enterprises, who come together to provide a market or indeed customer defined value or service. Emerging tele-computing technology facilitates this cooperation or networking of individual enterprises to meet market requirements.

Davidow \& Malone (1992) used the term "Virtual Company" to describe such an enterprise "To the outside observer, it will appear almost edgeless, with permeable and almost continuously changing interfaces among company, suppliers and customers". On a similar vein, the Chief Executive Officer of Intel (Andrew Grove) compared his business to - "...the theatre business in New York, which has an intinerant workforce of actors, directors, writers and technicians as well as experienced financial backers... By tapping into this network, you can quickly put a production together. It might be a smash hit ... or it might be panned by the critics. Inevitably the number of long running plays is small, but new creative ideas keep bubbling up".

The emergence of the Extended Enterprise would seem to be confirmed by the results of a survey of American manufacturing executives reported by Kim \& Miller in 1992. In order to understand changes taking place in the manufacturing environment, the respondents were questioned on the issues of globalisation, competition and cooperation and how they intended to respond to them. Among the programmes they intended to put in place were :

- Change communication patterns and abilities (identified by $32 \%$ of respondents).

- Move production and product development closer to markets (identified by $28 \%$ of respondents).

- Standardise processes and procedures [including ISO 9000 ] (identified by $26 \%$ of respondents). 
- Develop and expand partnerships and alliances (mentioned by $22 \%$ of respondents).

- Reengineer the supply chain among suppliers, distribution and sales (identified by $20 \%$ of respondents).

To quote directly from the report :

"The first type of challenge is to design and manage the implementation of physical changes in the location and responsibility of plants, R\&D centres, distribution centres and sales offices. These changes represent radical changes in the configuration of supply chains. The second type of challenge is to change or develop new external relationships, with suppliers, customers, and partners who interact with the supply chain...

Drucker in his 1990 article in the Harvard Business Review discussed the concept of systems oriented design, "in which the whole of manufacturing is seen as an integrated process that converts materials into goods, that is, into economic satisfactions". He suggested that "a few companies are even beginning to extend the systems concept beyond the plant and into the marketplace ..." As soon as we define manufacturing as a process that converts things into economic satisfactions, it becomes clear that producing does not stop when the product leaves the factory.

Bessant (1994) recognises the issue of inter-firm relationships. He sees a move away "from tight boundaries between firms to blurred boundaries, from 'arms length dealing' to co-operative relationships, from short term to long term relationships, and from confrontational to cooperative relationships/partnerships". Rightly however, Bessant distinguishes the emerging network model of partnerships between firms on the value chain from the vertically integrated firm - "Whereas earlier, more stable environments allowed vertically integrated firms to flourish, exploiting scale economies, the increasingly turbulent and fragmented pattern today requires firms to become focused on distinctive competencies...... The value of networks is that they.... behave as a single large firm with all the implications for flexible response, close contact with customers, manageable scale, innovation, etc."

In an earlier paper [Browne, Sackett and Wortmann 1994b], the extended enterprise was distinguished 'pictorially' as suggested in Figures 2 and 3 overleaf. In the past, the emphasis was an integration inside the four walls of the manufacturing plant (See Figure 2). Today the emphasis has changed to include the supply chain (integration of the supply chain through EDI and JIT) and the integration of manufacturing with distribution planning and control systems [See Figure 3].

In fact it has been argued, and indeed Figures 4 and 5 suggest that the Extended Enterprise represents a logical development of much of the efforts of manufacturing systems specialists over the past ten years or so. Approaches such as MRP, JIT, EDI, WCM, Lean Production, Concurrent Engineering, Supply Chain Management, DRP, Benchmarking and Business Process Re-engineering synthesise into the inter-enterprise networking model and ultimately realise the Extended Enterprise [See Browne, Sackett and Wortmann 1994b]. 


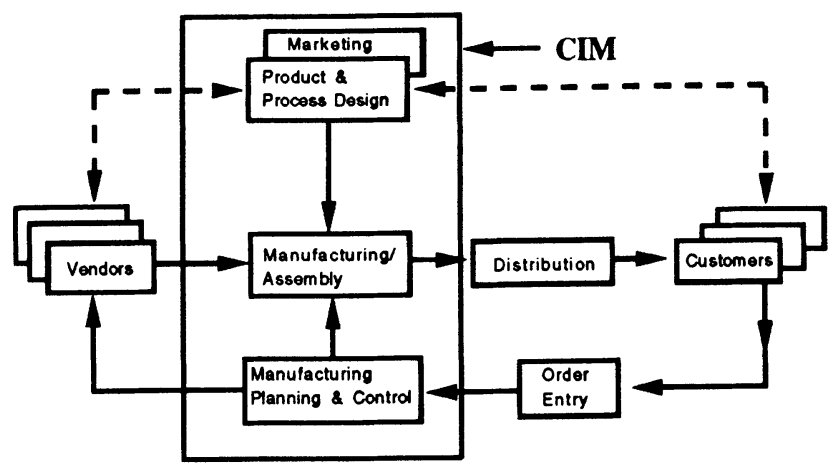

Figure 2 Computer Integrated Manufacturing.

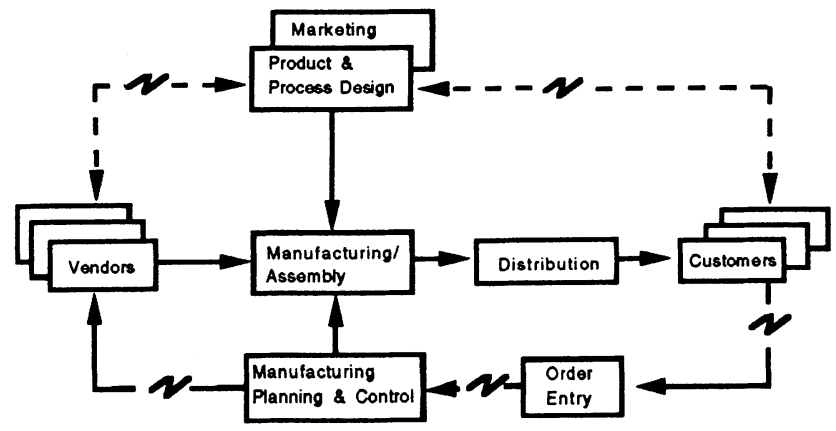

Figure 3 Electronic Data Interchange and The Extended Enterprise.

\section{THE EXTENDED ENTERPRISE A RESPONSE TO THE ENVIRONMENTAL CHALLENGE}

Today progressive manufacturing companies are developing a total life cycle approach to their products. Some companies are adapting a long term business objective of resource recovery. Resource recovery seeks to maximize the ability to recover products, components and materials and minimize the need for disposal sites through reuse, recycling, reclamation, resale, reconditioning and remanufacturing. In the past responsibility for products ended when the product left the manufacturing plants. Today, the situation has changed radically. The "system boundary", dipicted in Figure 4 overleaf has moved to include post consumer materials management.

Figure 5 overleaf indicates the current balance between reuse/refurbishment and waste disposal; also a more desirable balance for the future. 


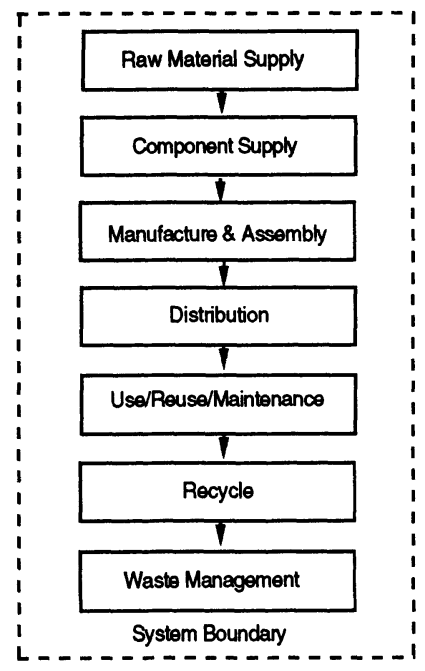

Figure 4 Total Product Life Cycle Perspective in Manufacturing.
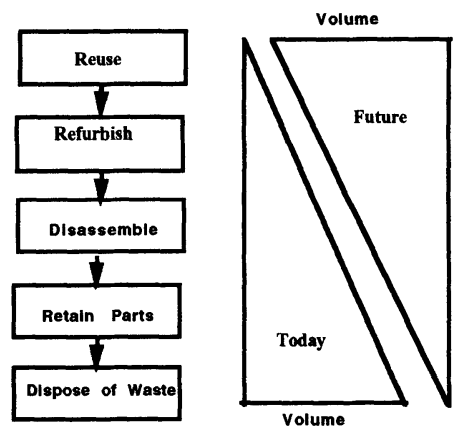

Figure 5 Resource Recovery - Todays Reality and Tomorrows Potential.

Major electronics and telecommunications manufacturing companies are setting up recycling plants to process returned products. Hewlett Packard processes 1200 tons of returned computer equipment in Grenoble each year. Sun claims to earn over $6 \mathrm{mECU}$ per annum by reselling old computer parts each year. In Holland, Rank Xerox and Oce disassemble and seek to reuse where possible returned photocopiers. Recently Alcatel, Siemens and Deutsche Telekom have announced a joint activity to recycle 12,000 tons of telephones, facsimile and similar equipment per year. 
To indicate the importance of the resource sustainment issue from a societal and environmental standpoint, we will use the Personal Computer (PC) industry to illustrate the issues. In 1965 the PC did not exist. Today there are estimated to be 140 million PCs in use in the world ( 1 for every 35 to 40 people). By the year 2010, PCs may well outnumber people. Within five to seven years virtually all current PCs will be discarded. It is estimated that plastics make up approximately $40 \%$ of the weight of a PC. The movement towards portable PCs increases the volume of hazardous material used in PCs; for example rechargeable batteries. Computer manufacturers are recognising the trends and are launching ecological programmes. They are beginning to offer 'Green PCs'. The PC manufacturers are beginning to realise that a combination of product takeback, modular design and remanufacturing may offer an environmentally and economically productive path to new product development (RSA, 94, Page 29). The takeback or resource recovery market is of course in it's early stages, and today the volume of consumer products which is taken back is relatively small. The market for secondary products and materials is emerging slowly. However it's importance for the future must not be underestimated.

Resource recovery, in the sense that it involves the original manufacturer taking responsibility for the 'end of life' disposal of his products represents an 'Extended Enterprise' approach.

\section{CHALLENGES FOR THE EXTENDED ENTERPRISE.}

Clearly the Extended Enterprise involves close collaboration between what were previously autonomous enterprises along the value chain. This implies thrust and the ability to share information which might previously have been considered company confidential. The establishment of such thrust and cooperation/collaboration is not made any easier by the constant changes which are taking place to individual elements of the value chain, and the impact which these changes have on the competitive positions of individual enterprises. Consider the partial value chain presented in Figure 6 . Assume for the sake of discussion that the contribution of each element to the valued added of the final product is normalised to $100 \%$. Consider the following assertions in the context of Figure 6.

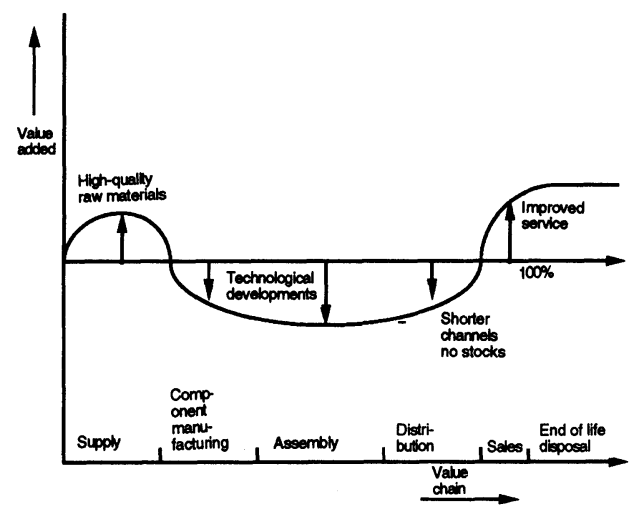

Figure 6 
1. New materials such as highly-alloyed steel, composite materials etc. are leading to an increase in value added in material supply. Material costs are rising in the long term, although in the short term the prices are determined by the general economic conditions and the particular situation in a particular industrial sector. However, nearly all metals, oil-based products and minerals are becoming more scarce and therefore more expensive in the long term.

2. The situation with components manufacture is complex. Increased functionality of components for example in electronics, results in expensive but high value added components. The multi-function component eliminates the need for assembly so the value added in assembly is passed back to the component stage.

3. Assembly is likely to move towards lower added cost also, because much functionality is already available in the components.

4. Physical distribution will probably involve lower costs if the interaction between the customer and the manufacturer becomes more intensive.

5. Improved service around the product will increase the added value in sales and after-sales activities.

Another important aspect of component manufacturing is a technological trend towards manufacturing systems where the marginal cost of an additional unit is approaching zero. Miniature products and software products are good examples of this. In fact in general all knowledgeware including for example books, entertainment, $\mathrm{CNC}$ code, multimedia software have a marginal cost of almost zero. Furthermore many of today's new products, particularly electronics, computer, consumer electronics and mechatronics products are dominated by embedded software.

The situation depicted in Figure 1 represents in macro terms what is happening in the computer industry where the "valued added" has, over the past five years or so, been pushed back into the components side [hence the rise of Intel and the cooperation between IBM, Apple and Motorola to develop the Power PC] and forward to the distribution and sales end [and the associated rise of Microsoft on the the one hand and Dell AST, Gateway 2000 on the other]. In effect assembly has become customer order driven, and together with efficient distribution channels has become a source of competitive advantage - customised products in extremely short lead times. In fact the computer industry provide an excellent example of the changing nature of relationships along the value chain, and the need for cooperation between what might ordinarily be considered competitors - in effect IBM "created" Microsoft in order to "sell" their original pc. Now IBM compete with Microsoft with their new "WARP" operating system. Similarly IBM and Apple competed through their respective "pc" and "mac" products. Now they cooperate and share the Powerpc processor. 


\section{SMES AND THE EXTENDED ENTERPRISE.}

SMEs (small and medium sized enterprises) involved in manufacturing seem to fall into two categories :

1. Those who are component manufacturers and who are largely involved in supplying components and assemblies to larger companies and final assemblers. Such SMEs are typically suppliers in sectors such as the automotive sector and the consumer electronics sector.

2. Those who are producers of finished products, such as SMEs tend to be in the capital goods business. For example, the vast majority of machine tool manufacturers in Europe are SMEs as are the majority of producers of moulds and dies.

For category 1 above, component suppliers on the supply chain, the emergence of the Extended Enterprise presents challenges as well as opportunities. Those who are willing (and financially able) to invest in developing appropriate systems e.g. ISO9000 accreditation, EDI links, EDE (Engineering Data Exchange) will benefit from the Extended Enterprise. Those who are weak technically and financially face tremendous difficulties. An indication of the extent of the problems and opportunities presented to supply chain component manufacturers in the automotive sector can be gleaned from a recent article in the Business Section of the newspaper "Independent on Sunday (1995)" headed "Japanese spur suppliers in two speed UK". The article goes on to suggest that "In Britain we are developing a two tier manufacturing sector, divided into those that supply the Japanese and those that don' $t$ ". It seems that the Japanese car assemblers who have located final assembly plants in the UK are putting tremendous efforts into supplier development - "those companies which get on to Japanese delivery schedules receive a bonus : a series of on site tutorials in Japanese trouble-shooting and production techniques. Those SMEs who adopt best practice through interaction with their Japanese customers are then in a position to bid successfully for work with European car makers.

It is also clear that for SMEs located in peripheral regions or in locations far from their customers (the final assemblers), there are added difficulties. For example within the European Union there are concerns that the emergence of inter-enterprise networking and the Extended Enterprise may lead to a situation where manufacturing enterprises located in peripheral regions of the EU may be placed at a disadvantage. Advanced telecommunications and computing systems (telecomputing) will certainly facilitate information flow within the EU an indeed the global economy, but physical geography will continue to place enterprises located in peripheral regions at a disadvantage in terms of rapid goods flow and logistics. Paradoxically the availability of telecomputing may well accentuate this disadvantage, particularly for traditional products which are expensive to transport. Of course for products which can be transported electronically (e.g. software) no such disadvantage exists and "peripheral" regions (in Europe, Ireland; in global terms India) can profit from the emerging global economy. 


\section{CONCLUSIONS.}

The Extended Enterprise where individual enterprises based on well defined core competencies cooperate to provide customer driven products is emerging. It is facilitated by the availability of tele-computing technology and is realised as a network of cooperating entities driven by a defined customer requirement. In the past the challenge to manufacturing systems researchers was to support integration within the four walls of the manufacturing plant. Today we must develop systems which support inter-enterprise networking across the value chain.

\section{REFERENCES.}

Bessant, J. (1994), “Towards Total Integrated Manufacturing", International Journal of Production Economics, Vol. 34, No.3, Pages 237-251.

Browne, J., Sackett, P.J., Wortmann, J.C. (1994a), "The Extended Enterprise - A Context for Benchmarking", Presented at the IFIP WG5.7 Workshop on Benchmarking - Theory and Practice, Trondheim, Norway, June 16-018.

Browne, J., Sackett, P.J., Wortmann, J.C. (1994b), "Industry Requirements and Associated Research Issues in the Extended Enterprise", Proceedings of the IMSE'94 European Workshop on Integrated Manufacturing Systems Engineering, Grenoble, France, December 12-14, 1994.

Davidow, W.H., Malone, M.S.(1992), "The Virtual Corporation”, Harper Business.

Drucker, P.F. (1990), "The Emerging Theory of Manufacturing”, Harvard Business Review, May-June 1990, Pages 94-102.

European Commission, (1994a), "Workprogramme for RTD in Information Technologies", Directorate General III Industry, Brussels.

European Commission, (1994b), "Workprogramme in Industrial and Materials Technologies", Directorate General XII, Science Research Development, Brussels.

Independent on Sunday (1995), "Japanese Spur Suppliers in Two-Speed UK", Business Section, Page 3, March 19th.

Keen, P. (1991), "Shaping the Future: Business Design through I.T.", Harvard Business School Press.

Kim, J.S., Miller, J.G., (1992), "Building the Value Factory : A Progress Report for US Manufacturing”, Executive Summary of the 1992 US Manufacturing Futures Survey, A Research Report of the Boston University School of Management Manufacturing Roundtable, Boston.

RSA, (1994), Environmental Design Workshops, "Ecodesign in the Telecommunications Industry", Published by RSA, 8 John Adam Street, London WC2N 6EZ.

Tipnis, V.J., 1993, "Evolving Issues in Product Life Cycle Design", Annals of the CIRP, Vol.42, No.4. 


\section{BIBLIOGRAPHY.}

Anon., (1991), "The Competitive Edge : Research Priorities for US Manufacturing, National Academy Press, Washington D.C.

Berger, S. Dertanzos, M., Lester, R., Solow, R., Thurow, L., (1989), “Toward a New Industrial America", Scientific American, June 1989, Vol.260, No.6, Pages 39-47.

Harman, R., Peterson, L., (1992), "Reinventing the Factory : Productivity Breakthroughs in manufacturing Today", The Free Press, New York.

Furukawa, Y., (1992), "Paradigm Shift in Manufacturing Systems - Forecasting Development Process toward 21st Century from Today's Intelligent CIM", Presentation at the Plenary Session of the 1992 IEEE International Conference on Robotics and Automation, Nice, France.

Nagel, R. Dove, R., (1991), "21st Century Manufacturing Enterprise Strategy - An Industry Led View", Iacocca Institute, Lehigh University.

Gruber, J., Tenenbaum, J.M., Weber, J.C., (1992), "Towards a Knowledge Medium for Collaborative Product Development”, Artificial Intelligence in Design, Editor:Gero, J.S., Kluwer Academic Publishers, Pages 413-432.

\section{BIOGRAPHY.}

Professor Jim Browne is Director of the CIM Research Unit (CIMRU) at University College Galway in Ireland. He has been engaged as a consultant by companies such as Digital Equipment Corporation, Westinghouse Electric, Apple Computers, De Beers, AT Cross and a number of Irish manufacturing companies, to work in areas such as manufacturing strategy, manufacturing systems simulation and production planning and control. He has also been engaged by the European Union to work on the development of the ESPRIT programme (DGIII) and the BRITE programme (DGXII). He has been engaged in EU research projects with industrial companies such as COMAU in Italy, Renault in France, DEC in Munich, Alcatel in France and a number of European Universities, including the University of Bordeaux, the University of Eindhoven, the University of Berlin and the University of Trondheim.

For the past two years, he has been engaged as a consultant on a project funded jointly by the EU and the State Scientific and Technical Committee of China (SSTCC) - (Peoples Republic of China) to support the National CIMS (Computer Integrated Manufacturing Systems) project of China. 